\title{
Metastasis from renal cell carcinoma to the thyroid 12 years after nephrectomy
}

\author{
Christopher J. Chin MD, Jason H. Franklin MD, Madeleine Moussa MBChB, Joseph L. Chin MD
}

Competing interests: None declared.

This article has been peer reviewed.

Correspondence to: Dr. Christopher J. Chin, cchin7@uwo.ca

CMAJ 2011. DOI:10.1503 /cmaj.092152
1 n 80-year-old woman presented to her primary care physician with a lump in her neck. On examination, the lump appeared to be a thyroid nodule, and a fineneedle aspiration biopsy was done. Twelve years earlier, renal cell carcinoma had been diagnosed and treated with radical nephrectomy and lymph node dissection. The pathology report at the time indicated renal cell carcinoma with Fuhrman nuclear grade IV/V. The resection margins were clear, and there was no evidence of invasion of the renal vein or capsule. The tumour was $4.5 \mathrm{~cm}$ at its greatest diameter, and all lymph nodes were negative for malignant disease (stage I). The patient's postoperative course and subsequent recuperation were uneventful. She did not receive adjuvant chemotherapy. Following surgery, she was monitored by her urologist and primary care physician for the first five years, after which care was transferred to her primary care physician.

The results of the fine-needle aspiration biopsy of the thyroid nodule showed atypical follicular cells. A hemithyroidectomy was done for diagnostic and therapeutic purposes. A nodule measuring $4.0 \times 3.0 \times 2.5 \mathrm{~cm}$ was found in the removed tissue.

Results of immunohistologic staining showed that the tumour cells were positive for CD10 and renal cell carcinoma antibody, which indicated that the nodule was a metastasis from the renal cell carcinoma excised 12 years earlier. The tumour cells were negative for thyroid transcription factor-1, thyroglobulin, mesothelial antibody, calcitonin, carcinoembryonic antigen, chromogranin A, parathyroid hormone, $\alpha$ inhibin, tyrosine hydroxylase, and

\section{KEY POINTS}

- Long-term surveillance of patients with renal cell carcinoma is warranted because metastases can present late (beyond a decade).

- Renal cell carcinoma most often metastasizes to the lung and bones, but it has been known to metastasize to unusual sites (e.g., inferior vena cava and thyroid).

- A thyroid nodule in a patient with a history of renal cell carcinoma should prompt fine-needle aspiration biopsy and testing for specific markers of renal cell carcinoma. cytokeratin 7 and 20. Computed tomography (CT) scans of the abdomen and thorax, obtained to rule out further metastases, were negative. The patient continues to have yearly follow-up visits with her primary care physician and, since the recurrence of her disease, has seen her urologist on an annual basis. She has remained free of disease since 2006.

\section{Discussion}

Renal cell carcinoma is the most common primary neoplasm of the kidney, accounting for $80 \%-85 \%$ of such neoplasms. ${ }^{1}$ Overall, this translates to about $2 \%$ of all cancers diagnosed each year. ${ }^{1}$ Renal cell carcinoma originates in the renal cortex and is characterized by a lack of early symptoms, which in the past often led to a late diagnosis. Since the advent of abdominal imaging (ultrasound and CT scans), an increasing proportion of patients with the disease have renal masses detected incidentally by abdominal imaging.

When a renal mass is found to be primary renal cell carcinoma, the treatment has traditionally been primarily surgical, because the tumour tends to be resistant to both chemotherapy (with the exception of new targeted therapies) and radiation therapy. As will be discussed later, targeted therapies, such as the new tyrosine kinase inhibitors and mammalian target of rapamycin (mTOR) inhibitors, are considerably more effective than previous chemotherapy regimens for widespread disease and have also replaced these regimens in the treatment of metastatic renal cell carcinoma. ${ }^{2}$

\section{How do metastases present?}

About $85 \%$ of metastases will occur within three years after the first surgical intervention. ${ }^{3}$ However, renal cell carcinoma is notorious for its late metastases. In 2006, Mumoli and colleagues published a report of a 58-year-old man who, while having an echocardiogram, was found to have a renal cell carcinoma metastasis protruding into his right atrium from the inferior vena cava, 25 years after nephrectomy. ${ }^{4}$

Renal cell metastases most often present in the 
lungs and bones (Table 1), but they can also present in unusual sites, such as skeletal muscle, skin and the pancreas. Late metastasis to the thyroid gland is relatively uncommon but potentially fatal. ${ }^{6}$ In one report that documented metastasis to the thyroid in eight patients, the median time from diagnosis of the primary tumour to diagnosis of the metastasis was 12 years (range $9-18$ years). ${ }^{?}$

\section{What tests should be ordered?}

In a patient with a history of renal cell carcinoma who presents with a thyroid nodule, current guidelines suggest fine-needle aspiration biopsy. ${ }^{8}$ Thyroid nodules are extremely common, especially when compared with a renal cell carcinoma metastasis. However, when fine-needle aspiration biopsy is ordered for a patient with a history of renal cell carcinoma, the pathologist needs to be asked to look for renal cell carcinoma using immunochemistry (e.g., CD10, cytokeratin 7 , vimentin and renal cell carcinoma marker [RCC Ma]) to help guide management. As well, it is useful to request that the pathologist stain for thyroid carcinoma markers, such as thyroglobulin, to rule out a primary thyroid tumour. Coordination and cooperation between the physician ordering the fine-needle aspiration biopsy and the pathologist are crucial to ensure that the proper stains are performed.

If a renal cell metastasis to the thyroid is diagnosed, the clinician should be aware of the potential for other sites of metastatic disease. It is important to verify that the metastatic disease is limited to the thyroid and has not spread to other locations.

\section{Who requires chemotherapy?}

Targeted therapies, such as tyrosine kinase inhibitors and mammalian target of rapamycin inhibitors have replaced traditional chemotherapy regimens in the treatment of metastatic renal cell carcinoma. ${ }^{2}$ However, these agents are still considerably toxic, and in a patient with a solitary, accessible metastatic lesion, a surgical approach is standard practice. In our patient, a thyroidectomy was done as definitive management. In the absence of residual disease, there is no evidence to support the use of targeted therapies.

\begin{tabular}{|lc|}
\hline $\begin{array}{l}\text { Table 1: Common sites of renal cell } \\
\text { carcinoma metastases }\end{array}$ \\
\hline Site & Frequency, $\%$ \\
\hline Lung & $50-60$ \\
\hline Bone & $30-40$ \\
\hline Liver & $30-40$ \\
\hline Brain & 5 \\
\hline
\end{tabular}

How long should patients be monitored? For stage I renal cell carcinoma, such as our patient had, the current Canadian guidelines for postoperative surveillance suggest that monitoring be done by the patient's urologist for at least six years after nephrectomy. ${ }^{9}$ The guidelines recommend that surveillance include yearly physical examination, chest radiographs and bloodwork (complete blood count, serum chemistries and liver function tests). ${ }^{9}$

For more advanced tumours, the intensity of surveillance is adjusted to reflect the increased likelihood of recurrence. In general, patients who present with a delayed metastasis (i.e., more than two years after nephrectomy) tend to have a better prognosis for recovery than those whose metastasis develops earlier. ${ }^{10}$

\section{Summary}

Although metastasis from renal cell carcinoma to the thyroid is relatively uncommon, it is a potentially lethal complication that can develop more than 10 years after the initial diagnosis of renal cell carcinoma. This report, as well as the others referenced in this paper, emphasize the need for continued long-term surveillance of patients who have renal cell carcinoma.

\section{References}

1. Kosary CL, McLaughlin JK. Kidney and renal pelvis. In: Miller BA, Ries LAG, Hankey BF, et al., editors. SEER cancer statistics review, 1973-1990. Bethesda (MD): National Cancer Institute; 1993. (NIH publication no. 93-2789, XI.1-XI.22)

2. Facchini G, Perri F, Caraglia M, et al. New treatment approaches in renal cell carcinoma. Anticancer Drugs 2009;20:893-900.

3. Sandock DS, Seftel AD, Resnick MI. A new protocol for the follow-up of renal cell carcinoma based on pathological stage. J Urol 1995;154:28-31.

4. Mumoli N, Cei M, Pasquinelli P, et al. Floating heart metastasis. J Am Soc Echocardiogr 2006;19:1293.e1-1293.e2.

5. Motzer RJ, Bander NH, Nanus DM. Renal-cell carcinoma N Engl J Med 1996;335:865-75.

6. Ritchie AWS, Chisholm GD. The natural history of renal cell carcinoma. Semin Oncol 1983;10:390-400.

7. Iesalnieks I, Trupka A, Raab M, et al. Renal cell carcinoma metastases to the thyroid gland -8 cases reported. Thyroid 2007; $17: 49-52$

8. Cooper DS, Doherty GM, Haugen BR, et al. Management guidelines for thyroid nodules and differentiated thyroid cancer. Thyroid 2006;16:109-42.

9. Kassouf W, Siemens R, Morash C, et al. Follow-up guidelines after radical or partial nephrectomy for localized and locally advanced renal cell carcinoma. Can Urol Assoc J 2009;3:73-6.

10. van der Poel HG, Roukema JA, Horenblas S, et al. Metastasectomy in renal cell carcinoma: a multicenter retrospective analysis. Eur Urol 1999;35:197-203.

Affiliations: From the Schulich School of Medicine and Dentistry (C.J. Chin); the Division of Urology, Department of Surgery (J.L. Chin); the Division of Surgical Oncology, Department of Oncology (Franklin, J.L. Chin); the Department of Otolaryngology - Head and Neck Surgery (C.J. Chin, Franklin); and the Department of Pathology (Moussa), University of Western Ontario, London, Ont.

Contributors: All of the authors contributed substantially to the writing or revising of the manuscript and approved the final version submitted for publication. 